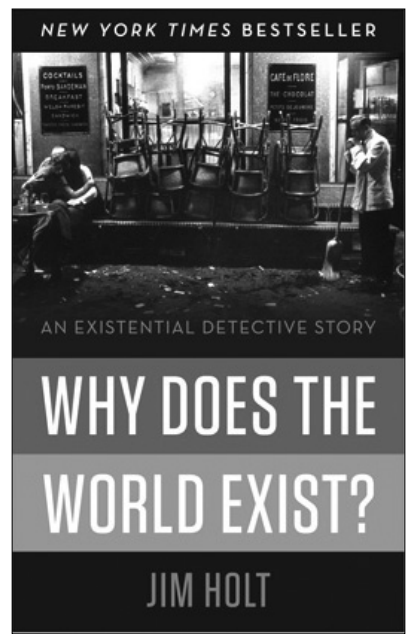

\section{The really, really big question}

\author{
MASSIMO PIGLIUCCI IS \\ ON THE TRAIL OF AN \\ EXISTENTIAL DETECTIVE
}

Why Does the World Exist? An Existential Detective Story by Jim Holt (Liveright), f12.95/\$27.95 $\boldsymbol{\square}$

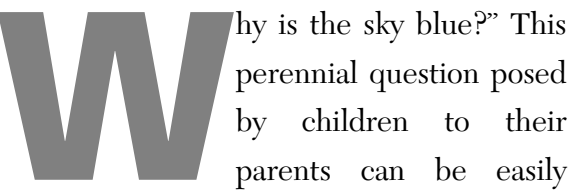
answered by modern moms and dads (after looking it up on Wikipedia): "Because the air scatters short-wavelength radiation better than long-wavelength radiation." Yes, of course, you then have to explain what "wavelength" and "radiation" are, but it's a start. No such easy answer is available for the question "Why is there something rather than nothing?" (for which Wikipedia returns a whopping 4,266 entries!). And that is the topic picked by Jim Holt for this lively philosophical-scientific quest concerning the ultimate metaphysical conundrum.

Holt sets up his pursuit as an "existential detective story", in which his own musings are mixed with the thoughts of a wide range of thinkers, from scientists to philosophers to theologians, several of whom he has interviewed. I was happy to see Holt talk to philosophers who are knowledgeable about the relevant science, as well as to scientists who have at least heard of the word "philosophy". I happen to think that the confluence of those two disciplines into what used to be called "scientia" (knowledge in the broader sense) is where a lot of the action is these days when it comes to a number of "deep questions", including consciousness, free will, morality, and the very structure of reality.

I was significantly less happy to have to endure a whole chapter devoted to the musings of Oxford theologian Richard Swinburne, since I think theology fails the test imposed by Hume's fork (that philosophical assertions need to have

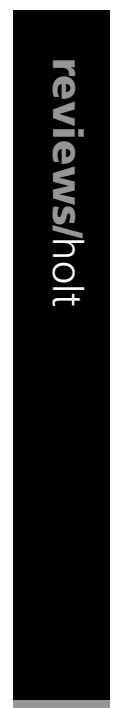


either empirical or mathematical content to be taken seriously), and that the best thing to do with it is to "Commit it then to the flames: for it can contain nothing but sophistry and illusion." I mean, here we are, at the onset of the twenty-first century, and we are still taking seriously people who tell us that God is the simplest "explanation" imaginable for the universe? Could it be that you think so because your imagination is limited, or because you are confused about what counts as an explanation?

But Holt - to his credit - goes to the other extreme as well, also paying a visit to Adolf Grünbaum in Pittsburgh. Grünbaum tells Holt that he is going after a pseudo-question, because nothingness is impossible, which in turn implies that "Why is there something rather than nothing?" is an example of "cadit quaestio", a fallen question, in response to which it is far better to go out and grab a beer (generally speaking, not a bad suggestion anyway).

Like Holt, however, I don’t share Grünbaum’s slightly too cavalier dismissal of the whole shebang, and think that science and philosophy actually do have a lot to say about it. Which brings the reader to an intellectual tour de force that includes multiverses and the many-worlds interpretation of quantum mechanics (which should really be kept more conceptually distinct than is done in some places in the book), mathematical Platonism, the idea that the universe may be a simulation in someone's computer (to which Holt gives remarkably little space, particularly compared to Swinburne's deeply unenlightening musings), and even more bizarre ideas - such as the possibility advanced by Plato that the universe may be the result of an ethical compulsion, or Robert Nozick's strange "principle of fecundity”.
One idea that I was hoping to see explored was James Ladyman and Don Ross's suggestion that there is no "ultimate" stuff of which the universe is made, that "at bottom" it's all about relations (don't ask "Relations between what?" because you'd be missing the point). While those authors do not explicitly endorse it, a universe in which "every thing must go" (as the title of their book puts it) is also one that is particularly friendly to certain forms of mathematical Platonism, which would have connected quite nicely with Holt's chapter on Pythagoras, Kurt Gödel, and Roger Penrose.

Regardless, throughout the book the reader will encounter - directly (based on interviews) or indirectly - the thoughts of some of the brightest and most provocative thinkers who have something to say about the deep questions, and two things clearly emerge from the volume. First, the question of why there is something rather than nothing is neither silly nor just of interest to philosophers and "armchair speculators". Second, like all good philosophy, by the end of the journey the prize is not necessarily getting an answer, but rather consists in gaining a much richer and more nuanced understanding of the question.

Of course, regardless of which take you end up favouring about the origin of all things, you might still come to agree with Douglas Adams: "In the beginning the Universe was created. This has made a lot of people very angry and has been widely regarded as a bad move." Or maybe not.

Massimo Pigliucci is professor of philosophy at the Graduate Center of the City University of New York. He is the author of the forthcoming Answers for Aristotle: How Science and Philosophy Can Lead Us to A More Meaningful Life (BasicBooks). His philosophical musings can be found at www.rationallyspeaking.org 